Article

\title{
E-Configuration Improves Antioxidant and Cytoprotective Capacities of Resveratrols
}

\author{
Jian Lin ${ }^{1,2,3}$, Xican Li ${ }^{4,5}, *$ (i) , Ban Chen ${ }^{4,5}$, Gang Wei ${ }^{4,5}$ and Dongfeng Chen $1,2, *$ (i) \\ 1 School of Basic Medical Science, Guangzhou University of Chinese Medicine, Waihuan East Road No. 232, \\ Guangzhou Higher Education Mega Center, Guangzhou 510006, China; linjianchn@outlook.com \\ 2 The Research Center of Basic Integrative Medicine, Guangzhou University of Chinese Medicine, \\ Waihuan East Road No. 232, Guangzhou Higher Education Mega Center, Guangzhou 510006, China \\ 3 School of Biomedical Sciences, Monash University, Melbourne Victoria 3001, Australia \\ 4 School of Chinese Herbal Medicine, Guangzhou University of Chinese Medicine, Waihuan East Road \\ No. 232, Guangzhou Higher Education Mega Center, Guangzhou 510006, China; \\ imchenban@foxmail.com (B.C.); weigang@gzucm.edu.cn (G.W.) \\ 5 Innovative Research \& Development Laboratory of TCM, Guangzhou University of Chinese Medicine, \\ Waihuan East Road No. 232, Guangzhou Higher Education Mega Center, Guangzhou 510006, China \\ * Correspondence: lixc@gzucm.edu.cn or lixican@126.com (X.L.); chen888@gzucm.edu.cn (D.C.); \\ Tel.: +86-203-935-8076 (X.L.)
}

Received: 27 June 2018; Accepted: 18 July 2018; Published: 20 July 2018

\begin{abstract}
The antioxidant and cytoprotective capacities of E-resveratrol and Z-resveratrol were compared using chemical and cellular assays. Chemical assays revealed that the two isomers were dose-dependently active in $\bullet \mathrm{O}_{2}{ }^{-}$-scavenging, ferric reducing antioxidant power (FRAP), $\mathrm{Cu}^{2+}$-reducing antioxidant capacity (CUPRAC), 2-phenyl-4,4,5,5-tetramethylimidazoline-1-oxyl 3-oxide radical (PTIO•)-scavenging ( $\mathrm{pH} 7.4$ and $\mathrm{pH} 4.5$ ), and 1,1-diphenyl-2-picryl-hydrazyl (DPPH•)-scavenging assays. The cellular assay indicated that the two isomers could also increase cell viabilities. However, quantitative analyses suggested that $E$-resveratrol exhibited stronger effects than Z-resveratrol in all chemical and cellular assays. Finally, the conformations of $E$-resveratrol and Z-resveratrol were analyzed. It can be concluded that both E-resveratrol and Z-resveratrol can promote redox-related pathways to exhibit antioxidant action and consequently protect bone marrow-derived mesenchymal stem cells (bmMSCs) from oxidative damage. These pathways include electron transfer (ET) and $\mathrm{H}^{+}$-transfer, and likely include hydrogen atom transfer (HAT). The E-configuration, however, improves antioxidant and cytoprotective capacities of resveratrols. The detrimental effect of the Z-configuration may be attributed to the non-planar preferential conformation, where two dihedral angles block the extension of the conjugative system.
\end{abstract}

Keywords: Z/E-configuration; antioxidant; Z-resveratrol; geometrical configuration; dihedral angle; bmMSCs; cytoprotective effect

\section{Introduction}

The carbon-carbon double bond $(\mathrm{C}=\mathrm{C})$ occurs widely in phenolic antioxidants, including phenolic phenylpropanoid [1], cinnamic acid derivatives [2], oligostilbenes [3], chalcones [4], flavonoids [5], and flavonoid glycosides [6]. The $\mathrm{C}=\mathrm{C}$ position has recently been suggested to alter antioxidant levels of phenolic antioxidants via conjugation [3,7]. As a planar covalent bond, $\mathrm{C}=\mathrm{C}$ may also present different geometrical configurations. These geometrical configurations may bring about different relative positions and interactions between functional groups. These interactions are hypothesized to affect the antioxidant capacity of phenolic antioxidants. However, no relevant studies regarding the effect of geometrical configuration on antioxidant capacity have been reported until now. 
Due to the central role of $\mathrm{C}=\mathrm{C}$ in the stilbene core, stilbene compounds were selected as the focus of this study. The most typical stilbene compound is trans-resveratrol (Figure 1A), which is widely found in red wine and many Chinese herbal medicines [8,9]. A great number of studies indicated that trans-resveratrol had beneficial effects on neurological diseases (e.g., Alzheimer disease [10], depressive symptoms [11]) and chronic diseases (e.g., hepatitis) [12,13]. The latest studies however suggested that it could also exhibit versatile activities, such as anti-cancer [14], anti-obesity [15], and anti-aging effects [16]. These effects are closely associated with antioxidant effects, in accordance with free radical biology and medicine [17]. Correspondingly, many studies focusing on the antioxidant effects and mechanisms of trans-resveratrol and the analogs have been reported [18-20]. Therefore, trans-resveratrol is considered to be an effective stilbene antioxidant. Usually, the so-called "resveratrol" in the literature refers to trans-resveratrol [13].

Strictly, the configuration of trans-resveratrol should be termed as the $E$-configuration, according to International Union of Pure and Applied Chemistry Rules [21]. Correspondingly, its isomer cis-resveratrol (Figure 1B) should be denominated Z-resveratrol. Hence, the two isomers E-resveratrol and Z-resveratrol provide an ideal pairing to research the effect of geometrical Z/E-configuration on the antioxidant properties of phenolics.

However, the issue has so far only been examined by computational chemists. In 2010, Mikulski and colleagues used computational chemistry to compare the radical scavenging activities of seven stilbenes (especially Z-resveratrol and E-resveratrol) in gas phase and water environments. All studied stilbenes had a higher hydrogen atom transfer (HAT) potential in the gas phase than in aqueous medium, where they were sensitive to electron transfer (ET) [22]. The study is obviously severely limited, because of the absence of experimental evidence from chemistry and biology.

A

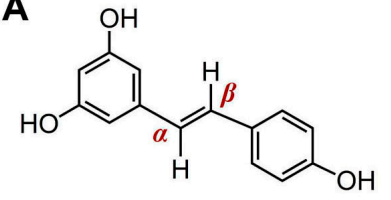

E-Resveratrol (trans-resveratrol)

D

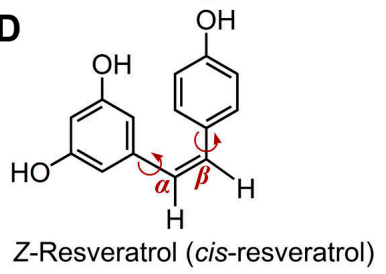

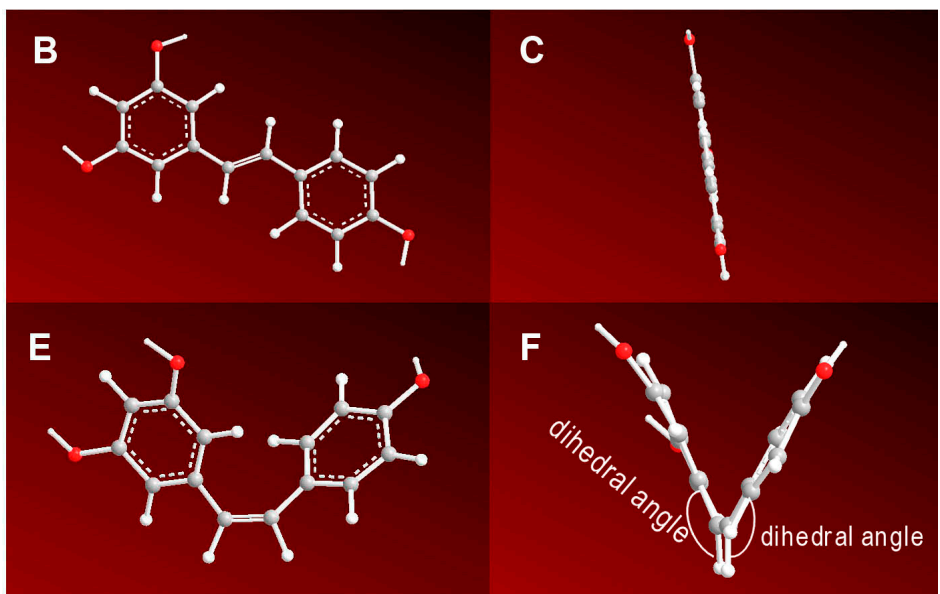

Figure 1. The configuration formula and molecular models of two resveratrols: (A) configuration formula of E-resveratrol; (B) preferential conformation-based ball-and-stick model of $E$-resveratrol (front view); (C) preferential conformation-based ball-and-stick model of $E$-resveratrol (right view); (D) configuration formula of Z-resveratrol; (E) preferential conformation-based ball-and-stick model of Z-resveratrol (front view); (F) preferential conformation-based ball-and-stick model of Z-resveratrol (right view). (The preferential conformation was created using ChemBioOffice 2014/Chem3D Pro.)

The reason why previous studies have been limited to computational chemistry, with no experimental chemistry, may be the fact that Z-resveratrol is chemically unstable. The $C=C$ in stilbenes generally displays the E-configuration [23]. As seen in Figure 1B, in the Z-resveratrol molecule, two benzo-rings are arrayed on one side of the $C=C$; this is therefore a crowded configuration with high molecular energy. Thus, it is difficult to prepare Z-resveratrol through common synthetic approaches. It is not available for commercial purchase. Compared to E-resveratrol, Z-resveratrol (Figure 1B) has received much less interest from scientists, possibly due to its difficulty of preparation. 
In the present study, authentic samples of Z-resveratrol, along with E-resveratrol were comparatively characterized using chemical and cellular assays. Chemical assays included $-\mathrm{O}_{2}{ }^{-}$-scavenging, ferric reducing antioxidant power (FRAP), $\mathrm{Cu}^{2+}$-reducing antioxidant capacity (CUPRAC), 2-phenyl-4,4,5,5-tetramethylimidazoline-1-oxyl 3-oxide radical (PTIO•)-scavenging (pH 7.4 and $\mathrm{pH} 4.5$ ), and 1,1-diphenyl-2-picryl-hydrazl (DPPH•)-scavenging assays. In the biological assay, bone marrow-derived mesenchymal stem cells (bmMSCs) acted as the cellular model. Due to the crucial role of bmMSCs in transplant engineering and beneficial effect of resveratrol in Alzheimer's disease [24], the study will provide new information on candidate antioxidant treatments for bmMSCs transplant engineering (particularly for the treatment of Alzheimer's disease). It will also provide definitive information on the role of the $Z / E$ configuration in phenolic antioxidants. These conclusions will aid the understanding of other similar phenolic antioxidants, including stilbenes (e.g., E-3,5-dihydroxystilbene and Z-3,5-dihydroxystilbene, Suppl. 1), and 2-phenyl-benzofuran-stilbene hybrids (e.g., maximol A and maximol B, Suppl. 2).

\section{Results and Discussion}

To provide supporting evidence in an experimental chemical system, the interaction of each resveratrol with reactive oxygen species (ROS) was explored using the pyrogallol autoxidation assay, a superoxide $\left(\bullet \mathrm{O}_{2}^{-}\right)$scavenging assay improved by our team [25]. The inhibition of pyrogallol autoxidation can characterize the $\bullet \mathrm{O}_{2}{ }^{-}$-scavenging levels of an antioxidant. As seen in Suppl. 3, the $\bullet \mathrm{O}_{2}{ }^{-}$-scavenging percentages of both isomers increased in a dose-dependent manner. This suggests that the two resveratrols had ROS-scavenging potential.

As one form of ROS-scavenging, $\bullet \mathrm{O}_{2}{ }^{-}$-scavenging has been suggested to be involved in several antioxidant pathways, including ET [26], $\mathrm{H}^{+}$-transfer [27], HAT [27], and proton-coupled electron transfer (PCET) [28,29]. These pathways are all fundamentally involved in ET and $\mathrm{H}^{+}$-transfer. The differences between them lie in the sequence of steps and their coordination. ET and $\mathrm{H}^{+}$-transfer simultaneously occur as a unit in the HAT pathway. However, ET and $\mathrm{H}^{+}$-transfer take place separately and subsequently in the PCET [30] and sequential electron proton transfer (SEPT) [31] pathways. However, the final outcome is identical, i.e., an antioxidant donates an electron and a proton to $\bullet \mathrm{O}_{2}{ }^{-}$. $\mathrm{H}^{+}$-transfer can cause protonated $\bullet \mathrm{O}_{2}{ }^{-}$, namely hydroperoxide $\left(\mathrm{HO}_{2} \bullet\right)[27,32] . \mathrm{HO}_{2} \bullet$ however has a much higher oxidation potential than $\bullet \mathrm{O}_{2}{ }^{-}$. ET can convert $\bullet \mathrm{O}_{2}{ }^{-}$into the stable $\mathrm{O}_{2}$ molecule to lower the redox potential $\left(\mathrm{E}_{0}{ }^{\prime}=0.31 \mathrm{~V}, \mathrm{pH} 7.0\right)$ [33]. Thus, ET plays a key role in $\bullet \mathrm{O}_{2}{ }^{-}$- and ROS-scavenging. The fact that two resveratrols can effectively scavenge the $\bullet \mathrm{O}_{2}{ }^{-}$-radical may indicate an ET potential in their antioxidant reactions.

To test the ET potential, the two resveratrols were further assessed by FRAP assay, a $\mathrm{Fe}^{3+}$-reducing reaction under acidic conditions ( $\mathrm{pH}$ 3.6) [34,35]. Such acidic conditions are believed to effectively suppress the $\mathrm{H}^{+}$-transfer from phenolics with weak acidity and thus the FRAP assay has been considered a purely ET reaction [36]. As shown in Suppl. 3, the FRAP values of both isomers increased in a strong dose-dependent manner, indicating that they had potential ET activity. In addition, at pH 7.4, both isomers were observed to increase the percentage of $\mathrm{Cu}^{2+}$-reducing in a strongly dose-dependent manner. This implies that, at physiological $\mathrm{pH}$, both isomers still possessed potential ET activity.

The two metal-reducing reactions $\left(\mathrm{Fe}^{3+}\right.$ - and $\mathrm{Cu}^{2+}$-reducing) are not identical radical-scavenging reactions and occur via distinct mechanisms. In order to provide evidence of ET in these radical-scavenging processes, the two isomers were further analyzed using a PTIO•-scavenging assay, a new method established by our team [37]. The PTIO•-scavenging assay can be conducted at various $\mathrm{pH}$ values in aqueous media. However, in aqueous buffer with $\mathrm{pH} \leq 5.0$, the PTIO•-scavenging reaction was confirmed by cyclic voltammetry to be a pure ET process $[37,38]$. The observations that both isomers had elevated PTIO•-scavenging ability at $\mathrm{pH} 4.5$ indicated that they were able to exhibit potential ET activity in the radical-scavenging reactions.

Unlike at $\mathrm{pH} 4.5$, $\mathrm{PTIO} \bullet$-scavenging at $\mathrm{pH} 7.4$ was regarded as being involved in $\mathrm{H}^{+}$-transfer. Through $\mathrm{H}^{+}$-transfer, $\mathrm{PTIO} \bullet$ was transformed into $[\mathrm{PTIO}-\mathrm{H}]^{+}$and the process could be monitored by 
HPLC-MS [37]. The findings that two isomers could effectively scavenge PTIO• at physiological pH 7.4, suggested that the two isomers might also undergo $\mathrm{H}^{+}$-transfer to scavenge radicals. The involvement of the $\mathrm{H}^{+}$-transfer pathway obviously accelerates the radical-scavenging reaction, thus, their $\mathrm{IC}_{50}$ values at $\mathrm{pH} 7.4$ always were lower than those at $\mathrm{pH} 4.5$ (Table 1).

Table 1. The $\mathrm{IC}_{50}$ values of $E$-resveratrol and Z-resveratrol in various antioxidant assays.

\begin{tabular}{|c|c|c|c|}
\hline Assays & $\begin{array}{c}E \text {-Resveratrol } \\
\mu \mathrm{M}\end{array}$ & $\begin{array}{c}\text { Z-Resveratrol } \\
\mu \mathrm{M}\end{array}$ & $\begin{array}{c}\text { Trolox } \\
\mu \mathrm{M}\end{array}$ \\
\hline$\bullet \mathrm{O}_{2}{ }^{-}$-scavenging & $345.3 \pm 5.5^{\mathrm{a}}$ & $448.2 \pm 4.9^{b}$ & $507.1 \pm 30.4^{\mathrm{c}}$ \\
\hline FRAP & $20.7 \pm 0.7^{\mathrm{a}}$ & $22.1 \pm 0.9^{\mathrm{a}}$ & $28.9 \pm 0.8^{c}$ \\
\hline $\mathrm{Cu}^{2+}$-reducing & $24.5 \pm 0.3^{\mathrm{a}}$ & $30.7 \pm 0.4^{\mathrm{b}}$ & $31.9 \pm 0.3^{c}$ \\
\hline PTIO•-scavenging ( $\mathrm{pH} 4.5)$ & $395.9 \pm 3.9$ a, B & $436.3 \pm 4.9^{\mathrm{b}, \mathrm{B}}$ & $206.9 \pm 6.5^{\mathrm{a}}$ \\
\hline PTIO•-scavenging ( $\mathrm{pH} 7.4$ ) & $157.7 \pm 3.2^{\mathrm{a}, \mathrm{A}}$ & $198.2 \pm 0.9^{\mathrm{b}, \mathrm{A}}$ & $383.8 \pm 8.8^{c}$ \\
\hline DPPH•-scavenging & $24.3 \pm 0.1^{\mathrm{a}}$ & $29.3 \pm 0.2^{c}$ & $25.6 \pm 0.2^{b}$ \\
\hline
\end{tabular}

The $\mathrm{IC}_{50}$ value was defined as the lowest concentration with $50 \%$ radical inhibition or relative reducing power, calculated by linear regression analysis, and expressed as the mean $\pm \mathrm{SD}(n=3)$. The linear regression was analyzed by Origin 6.0 professional software. The $\mathrm{IC}_{50}$ values with different superscripts $(\mathrm{a}, \mathrm{b}$, or $\mathrm{c})$ in the same row and the same column (A or B) are significantly different $(p<0.05)$. Trolox was the positive control.

As proposed by the computational chemistry [22], the two isomers preferentially underwent HAT (donating a hydrogen atom) to exert antioxidant activity in the gas phase. In our experiment with authentic samples, it was observed that the two resveratrols concentration-dependently scavenged $\mathrm{DPPH} \bullet$ radical (Suppl. 3); and their $\mathrm{IC}_{50}$ values were close to that of Trolox, a well-characterized antioxidant (Table 1). DPPH•-scavenging has been reported to include at least one HAT pathway, although there are other antioxidant pathways involved, such as proton-coupled electron transfer (PCET), sequential-proton-loss-electron-transfer (SPLET), single electron transfer (SET), and radical adduct formation (RAF) [39,40]. Thus, our findings provided experimental evidence of HAT pathway activity in two resveratrol isomers in chemical solution. To some extent, the evidence of DPPH•-scavenging can partly support the aforementioned $\mathrm{H}^{+}$-transfer and ET reactions, because HAT is regarded as a synergetic and simultaneous process of $\mathrm{H}^{+}$-transfer plus ET.

In short, both E-resveratrol and Z-resveratrol may act via similar pathways to exert their antioxidant actions. These pathways at least comprise $\mathrm{H}^{+}$-transfer and ET and possibly HAT. Essentially, these pathways are based on redox reactions.

However, the two resveratrols were quite different in their relative antioxidant levels. As seen in Table 1 , in all five antioxidant assays, E-resveratrol showed lower $\mathrm{IC}_{50}$ values than Z-resveratrol. This clearly suggested that $E$-resveratrol was a stronger antioxidant, compared to Z-resveratrol. Undoubtedly, such difference can be attributed to the geometrical configurations, i.e., $E$ /Z-configurations.

Seemingly, the $E / Z$-configuration merely alters the geometrical sites of two phenyl groups ( $\alpha$-phenyl and $\beta$-phenyl). In fact, such geometrical configuration can further cause differences in the molecule's preferential conformations. In the E-configuration, two phenyl groups can stably occupy the two sides of the $C=C$, thus they share a plane (Figure $1 B, C$ ). By comparison, in the $Z$-configuration, two phenyl groups cannot stably occupy one side of the $\mathrm{C}=\mathrm{C}$, because of the crowding; $\alpha$-phenyl and $\beta$-phenyl have to rotate their two $\sigma$ bonds to reduce the crowding as much as possible (Figure 1D-E). Thus, there are two dihedral angles, between the $\alpha$-phenyl plane and the $\alpha, \beta-\mathrm{C}=\mathrm{C}$ plane and between the $\beta$-phenyl plane and the planar $\alpha, \beta-\mathrm{C}=\mathrm{C}$ plane (Figure 1F). The whole $Z$-resveratrol molecule however is not on one plane. The existence of the dihedral angle effectively reduced the crowding of the two phenyl groups by introducing extensive steric hindrance. Therefore, the preferential conformations of Z-resveratrol and E-resveratrol are different; however, they are both generally stable. Our conformational analysis based on ChemBioOffice 2014/Chem3D Pro software (PerkinElmer, Guangzhou, China) was further supported by the computational chemistry, where the two dihedral angles in Z-resveratrol (Figure 1F) were calculated to be $39.22^{\circ}$ and $27.43^{\circ}$; 
while $E$-resveratrol has no dihedral angles. The molecular energies of both isomers were similarly calculated as -766.571045 hartree (approximately $-25.2 \mathrm{eV}$ ) [22].

It has been suggested that the antioxidant capacity of phenolics usually depends on the stability of their product after oxidation by free radicals (especially ROS) [41]. Irrespective of which pathway mediated the reaction, the two resveratrols oxidized by ROS can similarly produce a phenoxy radical, which may further be transferred into a semi-quinone (or even a quinone) form. Thus, the stability of the phenoxy radical may be responsible for the antioxidant capacity of a phenolic reactant. One mole of $E$-resveratrol reacts with $1 \mathrm{~mol} \mathrm{PTIO} \bullet$ via the $\mathrm{H}^{+}$-transfer plus ET pathways to generate a resveratrol phenoxy radical at the 4'-position [42]. As illustrated in Figure 2A, this phenoxy radical had a larger conjugative system. By comparison, $1 \mathrm{~mol} Z$-resveratrol reacts similarly with $1 \mathrm{~mol}$ PTIO• to give a phenoxy radical at the $4^{\prime}$-position (Figure $2 \mathrm{~B}$ ). However, the Z-resveratrol phenoxy radical is less stable than the E-resveratrol phenoxy radical. This is because the two dihedral angles block the extension of conjugation in the Z-resveratrol phenoxy radical. The reduced and scattered conjugation dictates the instability of the Z-resveratrol phenoxy radical, and, therefore, the weaker antioxidant capacity of $Z$-resveratrol as a reactant.

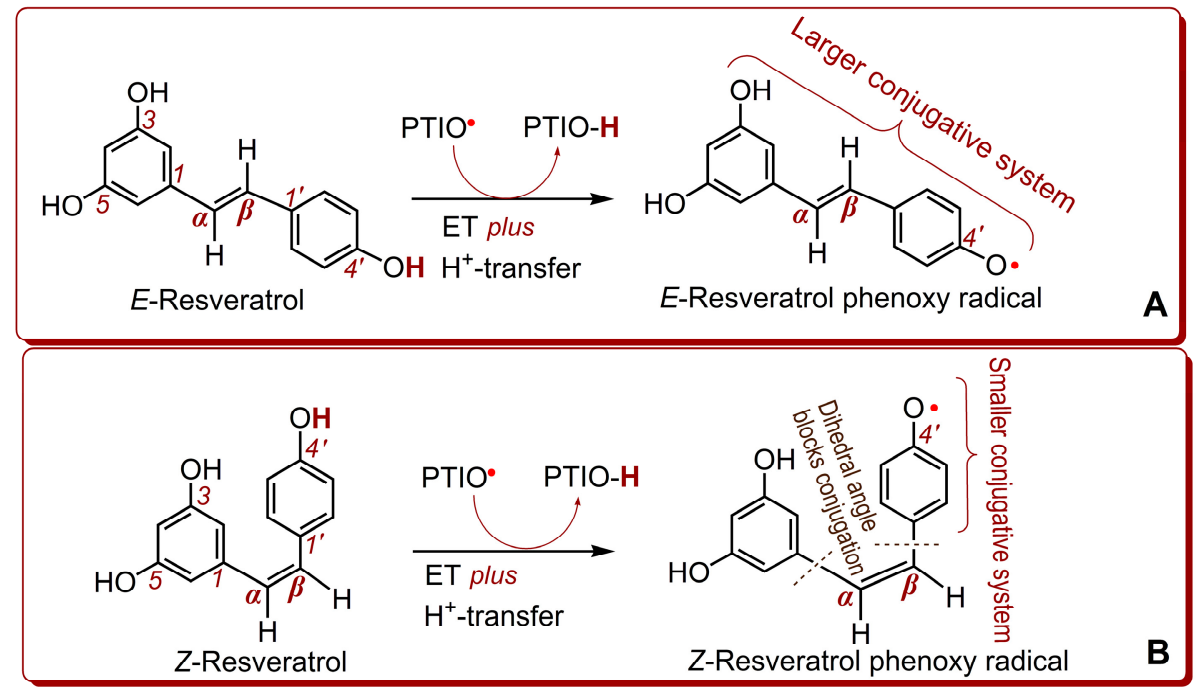

Figure 2. The proposed reactions of E-resveratrol (A) and Z-resveratrol (B) with PTIO radical via ET plus $\mathrm{H}^{+}$-transfer pathways.

To obtain biological evidence, the two resveratrols were incubated with bmMSCs damaged by $\mathrm{H}_{2} \mathrm{O}_{2}$ and Fenton reagent (an $\bullet \mathrm{OH}$ radical generator). The survival of bmMSCs was characterized by MTT assay [43]. As seen in Figure 3A,B, the two resveratrols could concentration-dependently increase the survival of bmMSCs at 10-100 $\mu \mathrm{M}$. Hence, both the resveratrols could resist not only $\mathrm{H}_{2} \mathrm{O}_{2}$, but also the $\bullet \mathrm{OH}$ radical, to protect bmMSCs from oxidative damage. This obviously supported the redox-related antioxidant pathways proposed above. However, as seen in Figure 3, E-resveratrol displayed a better cytoprotective effect than Z-resveratrol. The difference in cytoprotective effects is consistent with the difference in cytoprotective effect antioxidant effects.

In summary, both chemical and cellular evidence suggested that $E$-resveratrol had higher antioxidant and cytoprotective effects than Z-resveratrol. As the sole chemical difference between two resveratrols is their geometrical configuration, the geometrical configuration is likely to be fully responsible for these differences. Thus, it can be inferred that the E-configuration improved antioxidant and cytoprotective capacities of resveratrols. The reason for Z-resveratrol being inferior to $E$-resveratrol as an antioxidant cytoprotector is that the $Z$-configuration makes the functional group crowded, especially for such large groups. The crowded arrangement can further cause the preferential conformation to be a dihedral angle, which can destroy the molecular planarity. 
Non-planarity can block the formation of a larger conjugative system (especially $\pi-\pi$ conjugation). This greatly reduced the delocalization effect of the phenoxy radical and the phenoxy radical as an oxidized product correspondingly became unstable. The phenolic reactant was therefore inactivated in radical-scavenging reactions. These findings provide new understanding of the antioxidant effects of resveratrols and other phenolics, and will also help synthetic chemists to design more effective $\mathrm{C}=\mathrm{C}$-containing antioxidant candidates for bmMSC transplantation therapy [44,45]. In addition, these findings can explain the reason why E-resveratrol can widely occur in nature, and has versatile bioactivities [10-13,15,16].
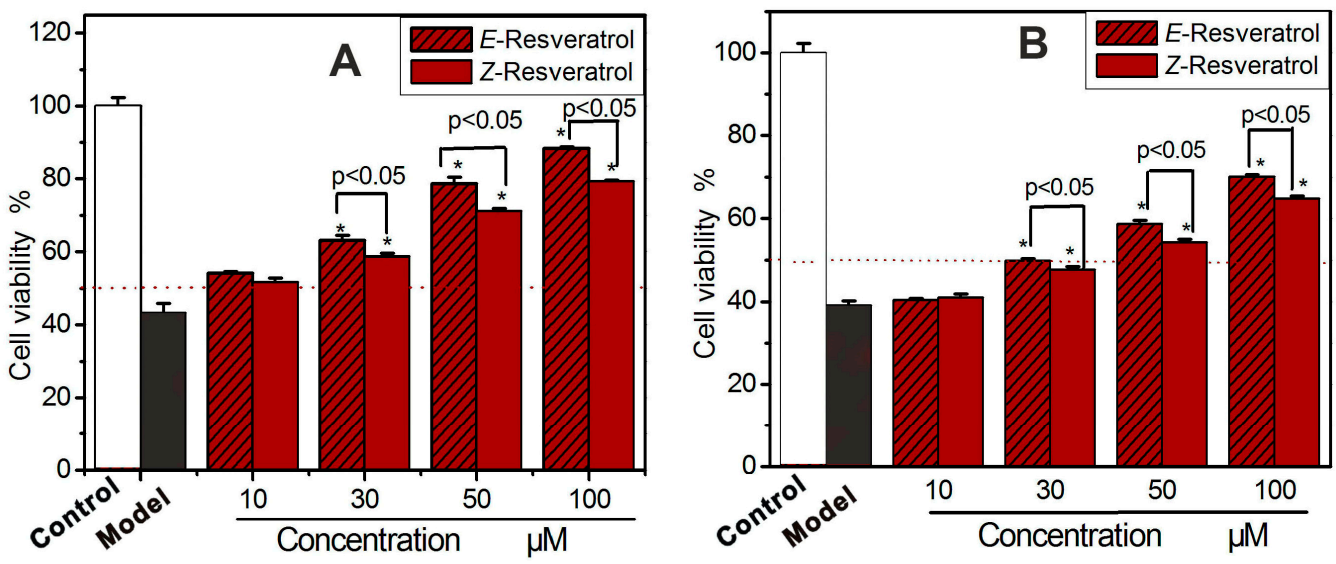

Figure 3. Cytoprotective effects of two resveratrols on oxidatively damaged bmMSCs: (A) bmMSCs were damaged by $\mathrm{H}_{2} \mathrm{O}_{2}$; (B) bmMSCs were damaged by Fenton reagent (i.e., addition of $100 \mu \mathrm{M} \mathrm{FeCl}_{2}$ followed by $50 \mu \mathrm{M} \mathrm{H}_{2} \mathrm{O}_{2}$ ). The control group was cultured in medium only, while the model group was treated with $\mathrm{H}_{2} \mathrm{O}_{2}$ (or Fenton reagent). The resveratrol group was damaged by $\mathrm{H}_{2} \mathrm{O}_{2}$ (or Fenton reagent) followed by $E$ - or Z-resveratrol. Each value is expressed as the mean $\pm \mathrm{SD}, n=3$; * Significant difference $v s$ the model group, $p<0.05$. Cell viability was assessed using the MTT method. bmMSCs, bone marrow-derived mesenchymal stem cells; MTT, methyl thiazolyl tetrazolium.

\section{Materials and Methods}

\subsection{Animals and Chemicals}

Sprague-Dawley (SD) rats at 4 weeks of age were obtained from the animal center of the Guangzhou University of Chinese Medicine. The protocol of this experiment was performed under the supervision of the Institutional Animal Ethics Committee at the Guangzhou University of Chinese Medicine. Other reagents were of analytical grade. E-Resveratrol (CAS 501-36-0, $\mathrm{C}_{14} \mathrm{H}_{12} \mathrm{O}_{3}$, M.W. 228.2, purity 97\%) was obtained from BioBioPha Co., Ltd. (Kunming, China, Suppl. 4); Z-resveratrol (CAS 61434-67-1, $\mathrm{C}_{14} \mathrm{H}_{12} \mathrm{O}_{3}$, M.W. 228.2, purity 97\%, Suppl. 4) was kindly donated by the School of Biomedical Sciences, Monash University (Melbourne, Australia). 1,1-Diphenyl-2-picrylhydrazyl radical (DPPH•), ( \pm )-6-hydroxyl-2,5,7,8-tetramethylchromane-2-carboxylic acid (Trolox), pyrogallol, and 2,9-dimethyl-1,10-phenanthroline (neocuproine) were purchased from Sigma-Aldrich Shanghai Trading Co. (Shanghai, China). 2,4,6-Tripyridyltriazine (TPTZ), pyrogallol, and 3-(4,5-dimethylthiazol2-yl)-2,5-diphenyltetrazolium bromide (MTT) were obtained from Sigma-Aldrich Shanghai Trading Co. Dulbecco's modified Eagle's medium (DMEM) and fetal bovine serum (FBS) were purchased from Gibco (Grand Island, NY, USA). CD44 and Proteinase K were purchased from Wuhan Boster Co., Ltd. (Wuhan, China). All other reagents were of analytical grade.

\subsection{Superoxide Anion $\left(\bullet \mathrm{O}_{2}^{-}\right)$Scavenging Assay}

Superoxide anion $\left(\bullet \mathrm{O}_{2}{ }^{-}\right)$inhibiting activity was measured using a pyrogallol autooxidation method that was previously improved by our laboratory [41]. Briefly, the sample was dissolved in 
methanol at $1 \mathrm{mg} / \mathrm{mL}$. The sample solution $(x=50-250 \mu \mathrm{L})$ was mixed with Tris-HCl buffer $(980-x \mu \mathrm{L}$, $0.05 \mathrm{M}$, pH 7.4) containing EDTA (1 mM). After $20 \mu \mathrm{L}$ pyrogallol $(60 \mathrm{mM}$ in $1 \mathrm{mM} \mathrm{HCl})$ was added, the mixture was vigorously shaken at room temperature. The absorbance of the mixture was measured (Unico 2100, Shanghai, China) at $325 \mathrm{~nm}$ every $30 \mathrm{~s}$ for $5 \mathrm{~min}$. Tris-HCl buffer was used as a blank. The $\bullet \mathrm{O}_{2}{ }^{-}$inhibiting ability was calculated as follows:

$$
\text { Inhibition } \%=\frac{\left(\frac{A_{325 n \text { m }, \text { control }}}{T}-\frac{A_{325 n m, \text { sample }}}{T}\right)}{\left(\frac{A_{325 n \text { m control }}}{T}\right)} \times 100 \%
$$

where $\Delta A_{325 \mathrm{~nm}}$, control is the increment in the absorbance at $325 \mathrm{~nm}\left(A_{325 \mathrm{~nm}}\right)$ of the mixture without the sample and $\Delta A_{325 \mathrm{~nm}}$, sample is the increment in $A_{325 \mathrm{~nm}}$ of the mixture including the sample; $T=5 \mathrm{~min}$.

\subsection{Ferric-Reducing Antioxidant Power (FRAP) Assay}

The FRAP assay was adapted from Benzie and Strain [46]. Briefly, the FRAP reagent was freshly prepared by mixing $10 \mathrm{mM}$ TPTZ, $20 \mathrm{mM} \mathrm{FeCl}_{3}$, and $0.25 \mathrm{M} \mathrm{pH} 3.6$ acetate buffer at 1:1:10 (volume ratio). The test sample $(x=2-10 \mu \mathrm{L}, 0.5 \mathrm{mg} / \mathrm{mL})$ was added to $(20-x) \mu \mathrm{L}$ of $95 \%$ ethanol followed by $80 \mu \mathrm{L}$ of FRAP reagent. The absorbance was measured at $595 \mathrm{~nm}$ after a $30 \mathrm{~min}$ incubation at ambient temperatures using distilled water as the blank. The relative reducing power of the sample compared to the maximum absorbance was calculated using the following formula:

$$
\text { Relative reducing effect } \%=\frac{A-A_{\min }}{A_{\max }-A_{\min }} \times 100 \%
$$

where $A_{\max }$ is the maximum absorbance at $595 \mathrm{~nm}$ and $A_{\min }$ is the minimum absorbance in the test. $A$ is the absorbance of the sample.

\subsection{Cupric Ions $\left(\mathrm{Cu}^{2+}\right)$ Reducing Antioxidant Capacity (CUPRAC) Assay}

The cupric ion reducing antioxidant capacity (CUPRAC) assay was determined based on the method proposed by Apak et al. [47], with small modifications as presented in the literature of Tian [48]. Twelve microliters $\mathrm{CuSO}_{4}$ solution $(0.01 \mathrm{M})$ and $12 \mu \mathrm{L}$ ethanolic neocuproine solution $\left(7.5 \times 10^{-3} \mathrm{M}\right)$ were added to a 96-well and mixed with different concentrations of samples $(3-15 \mu \mathrm{g} / \mathrm{mL})$. The total volume was then adjusted to $100 \mu \mathrm{L}$ with a $\mathrm{CH}_{3} \mathrm{COONH}_{4}$ buffer solution $(0.1 \mathrm{M})$, and mixed again to homogenize the solution. The mixture was maintained at room temperature for $30 \mathrm{~min}$, and the absorbance was measured at $450 \mathrm{~nm}$ on a microplate reader (Multiskan FC, Thermo Scientific, Shanghai, China). The relative reducing power of the sample was calculated using the formula in Section 3.3.

\subsection{PTIO•-Scavenging Assays}

The PTIO•-scavenging assays (at $\mathrm{pH} 4.5$ or $\mathrm{pH} 7.4$ ) were conducted based on our previously described method [32]. In brief, the test sample solution $(x=2-10 \mu \mathrm{L}, 1 \mathrm{mg} / \mathrm{mL})$ was added to $(20-x) \mu \mathrm{L}$ of $95 \%$ ethanol, followed by $80 \mu \mathrm{L}$ of an aqueous PTIO• solution. The aqueous PTIO• solution was prepared using a phosphate-butter solution $(0.1 \mathrm{mM}, \mathrm{pH} 4.5$ or $\mathrm{pH} 7.4)$. The mixture was maintained at $37^{\circ} \mathrm{C}$ for $2 \mathrm{~h}$, and the absorbance was then measured at $560 \mathrm{~nm}$ using the aforementioned microplate reader. The PTIO• inhibition percentage was calculated as follows:

$$
\text { Inhibition } \%=\frac{A_{0}-A}{A_{0}} \times 100 \%
$$

where $A_{0}$ is the absorbance of the control without the sample and $A$ is the absorbance of the reaction mixture with the sample. 


\subsection{DPPH•-Scavenging Assay}

$\mathrm{DPPH} \bullet$ radical scavenging activity was determined as previously described [49]. Briefly, $80 \mu \mathrm{L}$ of DPPH• solution $(0.1 \mathrm{~mol} / \mathrm{L})$ was mixed with methanolic sample solutions with the indicated concentration $(0.05 \mathrm{mg} / \mathrm{mL}, 5-25 \mu \mathrm{L})$. The mixture was maintained at room temperature for $30 \mathrm{~min}$ and the absorbance was measured at $519 \mathrm{~nm}$ on a microplate reader. The percentage of DPPH• scavenging activity was calculated using the equation described in Section 3.5.

\subsection{Protective Effect Against Fenton-induced Damage to bmMSCs (MTT assay)}

bmMSCs culture was carried out according to our previous report [50] with slight modifications. bmMSCs at passage 3 were analyzed for cell homogeneity based on CD44 expression by flow cytometry (Figure 4A). The protective effect of resveratrols against oxidative damage of bmMSCs was evaluated using the MTT assay [51]. The experimental protocol is briefly illustrated in Figure 4B.

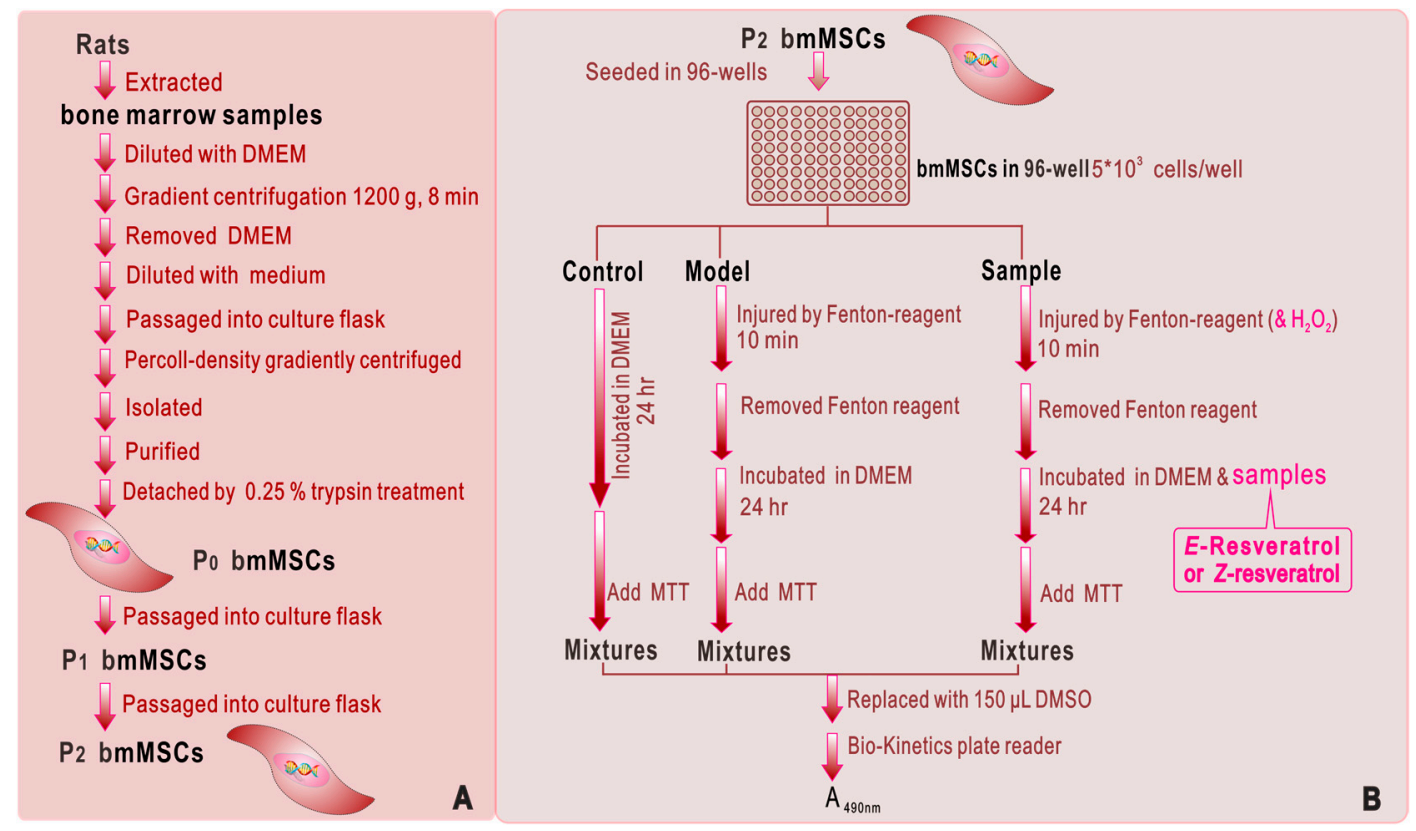

Figure 4. Experimental procedures for the preparation and culture of bmMSCs (A) and for the MTT assay (B). Each test was repeated in five independent wells. Fenton reagent: $\mathrm{FeCl}_{2}(100 \mu \mathrm{M})$ followed by $\mathrm{H}_{2} \mathrm{O}_{2}(50 \mu \mathrm{M})$; MTT: $5 \mathrm{mg} / \mathrm{mL}$ in PBS, $20 \mu \mathrm{L}$; PE-1420 Bio-Kinetics reader: Bio-Kinetics Corporation, Sioux Center, IA, USA.

\subsection{Statistical Analysis}

Each experiment was performed in triplicate and the data were recorded as mean $\pm \mathrm{SD}$ (standard deviation). The dose-response curves were plotted using Origin 6.0 professional software (OriginLab, Northampton, MA, USA). The $\mathrm{IC}_{50}$ value was defined as the final concentration of $50 \%$ radical inhibition (or relative reducing power) [52]. It was calculated by linear regression analysis and expressed as the mean $\pm \mathrm{SD}(n=3)$. The linear regression was analyzed using Origin 6.0. Determination of significant differences between the mean $\mathrm{IC}_{50}$ values was performed using one-way ANOVA and the $t$-test. The analysis was performed using SPSS software 13.0 (SPSS Inc., Chicago, IL, USA) for windows. $p<0.05$ was considered to be statistically significant.

\section{Conclusions}

Both E-resveratrol and Z-resveratrol can induce redox-related pathways to exhibit antioxidant action. These pathways include ET and $\mathrm{H}^{+}$-transfer and may include HAT. Thus, antioxidant 
resveratrols can protect bmMSCs from oxidative damage. However, E-resveratrol always exhibited stronger antioxidant and cytoprotective effects than Z-resveratrol. The difference can be attributed to the existence of two dihedral angles, which destroy the molecular planarity and thus block the extension of the conjugative system. In other words, the Z-configuration plays a detrimental role and the $E$-configuration improves antioxidant and cytoprotective capacities of resveratrols.

Supplementary Materials: The following are available online: Suppl. 1, The configuration formula of E-3,5-dihydroxystilbenen and Z-3,5-dihydroxystilbenen; Suppl. 2, The configuration formula of maximol A and maximol B; Suppl. 3, Dose-response curves; Suppl. 4 The certificate of analysis E-resveratrol and Z-resveratrol.

Author Contributions: J.L. and D.C. conceived and designed the experiments; J.L. performed the experiments; B.C. analyzed the experimental data; X.L. wrote the paper. G.W. revised the paper. All authors read and approved the final manuscript.

Funding: This work was supported by Guangdong Provincial Education Office Science and Technology Project (2017KCXTD007), the National Nature Science Foundation of China (81573558), Natural Science Foundation of Guangdong Province (2017A030312009), and Guangdong Science and Technology Project (2017A050506043).

Acknowledgments: Z-Resveratrol was donated by School of Biomedical Sciences, Monash University (Melbourne, Australia).

Conflicts of Interest: The authors declare that they have no competing interests.

\section{Abbreviations}

The following abbreviations are used in this manuscript:

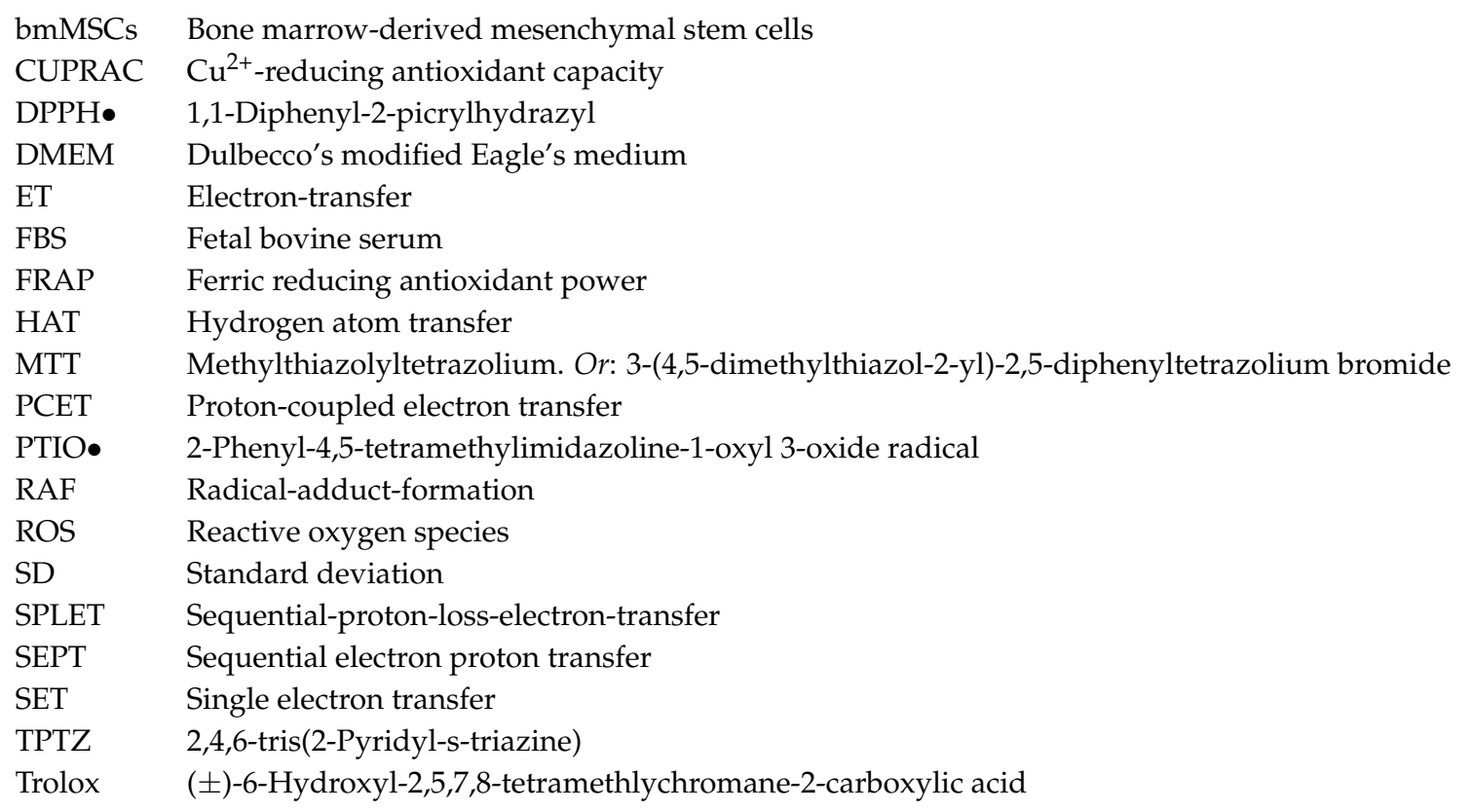

\section{References}

1. Li, X.; Xie, Y.; Li, K.; Wu, A.; Xie, H.; Guo, Q.; Xue, P.; Maleshibek, Y.; Zhao, W.; Guo, J.; et al. Antioxidation and cytoprotection of acteoside and its derivatives: Comparison and mechanistic chemistry. Molecules 2018, 23, 498. [CrossRef] [PubMed]

2. Wang, X.Z.; Li, X.C.; Chen, D.F. Evaluation of antioxidant activity of isoferulic acid in vitro. Nat. Prod. Commun. 2011, 6, 1285-1288. [PubMed]

3. Li, X.; Xie, Y.; Xie, H.; Yang, J.; Chen, D. $\pi-\pi$ Conjugation Enhances Oligostilbene's Antioxidant Capacity: Evidence from $\alpha$-Viniferin and Caraphenol A. Molecules 2018, 23, 694. [CrossRef] [PubMed]

4. Li, X.C.; Liu, J.J.; Zhao, Z.X.; Wang, T.T.; Lin, J.; Chen, D.F. Effects of Natural ChalconeTannin Hybrids Protecting Mesenchymal Stem Cells against ROS-mediated Oxidative Damage and Indexes for Antioxidant Mechanisms. Chem. Lett. 2016, 45, 743-745. [CrossRef] 
5. Li, X.; Jiang, Q.; Wang, T.; Liu, J.; Chen, D. Comparison of the antioxidant effects of quercitrin and isoquercitrin: Understanding the role of the 6"-OH group. Molecules 2016, 21, 1246. [CrossRef] [PubMed]

6. Li, X.C.; Mai, W.Q.; Chen, D.F. Chemical study on protective effect against hydroxyl-induced DNA damage and antioxidant mechanism of myricitrin. J. Chin. Chem. Soc-Taip. 2014, 61, 383-391. [CrossRef]

7. Li, X.; Xie, H.; Zhan, R.; Chen, D. Effect of double bond position on 2-phenyl-benzofuran antioxidants: A comparative study of moracin C and iso-moracin C. Molecules 2018, 23, 754. [CrossRef] [PubMed]

8. Cai, L.; Koziel, J.A.; Dharmadhikari, M.; Hans van Leeuwen, J. Rapid determination of trans-resveratrol in red wine by solid-phase microextraction with on-fiber derivatization and multidimensional gas chromatography-mass spectrometry. J. Chromatogr. A 2009, 1216, 281-287. [CrossRef] [PubMed]

9. Zhang, Q.F.; Cheung, H.Y. Development of capillary electrophoresis fingerprint for quality control of rhizoma Smilacis Glabrae. Phytochem. Anal. 2011, 22, 18-25. [CrossRef] [PubMed]

10. Sawda, C.; Moussa, C.; Turner, R.S. Resveratrol for Alzheimer's disease. Ann. N.Y. Acad. Sci. 2017, 1403, 142-149. [CrossRef] [PubMed]

11. Chen, W.J.; Du, J.K.; Hu, X.; Yu, Q.; Li, D.X.; Wang, C.N.; Zhu, X.Y.; Liu, Y.J. Protective effects of resveratrol on mitochondrial function in the hippocampus improves inflammation-induced depressive-like behavior. Physiol. Behav. 2017, 182, 54-61. [CrossRef] [PubMed]

12. Pennisi, M.; Bertino, G.; Gagliano, C.; Malaguarnera, M.; Bella, R.; Borzi, A.M.; Madeddu, R.; Drago, F.; Malaguarnera, G. Resveratrol in Hepatitis C Patients Treated with Pegylated-Interferon- $\alpha$-2b and Ribavirin Reduces Sleep Disturbance. Nutrients 2017, 9, 897. [CrossRef] [PubMed]

13. Vervandier-Fasseur, D.; Vang, O.; Latruffe, N. Special Issue: Improvements for Resveratrol Efficacy. Molecules 2017, 22, 1737. [CrossRef] [PubMed]

14. Huminiecki, L.; Horbanczuk, J. The functional genomic studies of resveratrol in respect to its anti-cancer effects. Biotechnol. Adv. 2018. [CrossRef] [PubMed]

15. Pan, M.H.; Wu, J.C.; Ho, C.T.; Lai, C.S. Antiobesity molecular mechanisms of action: Resveratrol and pterostilbene. Biofactors 2018, 44, 50-60. [CrossRef] [PubMed]

16. Li, Y.R.; Li, S.; Lin, C.C. Effect of resveratrol and pterostilbene on aging and longevity. Biofactors 2018, 44, 69-82. [CrossRef] [PubMed]

17. Zheng, R.L.; Huang, Z.Y. Free Radical Biology, 1st ed.; Higher Education Press: Beijing, China, 2007; p. 143.

18. Pan, Y.; Zhang, H.; Zheng, Y.; Zhou, J.; Yuan, J.; Yu, Y.; Wang, J. Resveratrol Exerts Antioxidant Effects by Activating SIRT2 To Deacetylate Prx1. Biochemistry 2017, 56, 6325-6328. [CrossRef] [PubMed]

19. Santos, J.A.; de Carvaho, G.S.; Oliveira, V.; Raposo, N.R.; da Silva, A.D. Resveratrol and analogues: A review of antioxidant activity and applications to human health. Recent Pat. Food Nutr. Agric. 2013, 5, 144-153. [CrossRef] [PubMed]

20. Kotora, P.; Šeršeň, F.; Filo, J.; Loos, D.; Gregáň, J.; Gregáň, F. The Scavenging of DPPH, Galvinoxyl and ABTS Radicals by Imine Analogs of Resveratrol. Molecules 2016, 21, 21. [CrossRef] [PubMed]

21. Graham, S.T.W.; Fryhle, B.C. Organic Chemistry, 8th ed; Chemical Industry Press: Beijing, China, 2004; pp. 288-289.

22. Mikulski, D.; Gorniak, R.; Molski, M. A theoretical study of the structure-radical scavenging activity of trans-resveratrol analogues and cis-resveratrol in gas phase and water environment. Eur. J. Med. Chem. 2010, 45, 1015-1027. [CrossRef] [PubMed]

23. Yang, J.S. ${ }^{13}$ C-NMR Spectroscopic Databook of Natural Products; Chemical Industry Press: Beijing, China, 2011; pp. 2244-2277.

24. Wang, X.; Ma, S.; Yang, B.; Huang, T.; Meng, N.; Xu, L.; Xing, Q.; Zhang, Y.; Zhang, K.; Li, Q.; et al. Resveratrol promotes hUC-MSCs engraftment and neural repair in a mouse model of Alzheimer's disease. Behav. Brain. Res. 2018, 339, 297-304. [CrossRef] [PubMed]

25. Li, X.C. Improved pyrogallol autoxidation method: A reliable and cheap superoxide-scavenging assay suitable for all antioxidants. J. Agric. Food Chem. 2012, 60, 6418-6424. [CrossRef] [PubMed]

26. Jovanovic, S.V.; Hara, Y.; Steenken, S.; Simic, M.G. Antioxidant Potential of Gallocatechins. A Pulse Radiolysis and Laser Photolysis Study. J. Am. Chem. Soc. 1995, 117, 9881-9888. [CrossRef]

27. Holtomo, O.; Nsangou, M.; Fifen, J.J.; Motapon, O. DFT study of the effect of solvent on the H-atom transfer involved in the scavenging of the free radicals $\bullet \mathrm{HO}_{2}$ and $\bullet \mathrm{O}_{2}{ }^{-}$by caffeic acid phenethyl ester and some of its derivatives. J. Mol. Model. 2014, 20, 2509. [CrossRef] [PubMed] 
28. Nakayama, T.; Uno, B. Importance of Proton-Coupled Electron Transfer from Natural Phenolic Compounds in Superoxide Scavenging. Chem. Pharm. Bull. (Tokyo) 2015, 63, 967-973. [CrossRef] [PubMed]

29. Quintero-Saumeth, J.; Rincón, D.A.; Doerr, M.; Daza, M.C. Concerted double proton-transfer electron-transfer between catechol and superoxide radical anion. Phys. Chem. Chem. Phys. 2017, 19, 26179-26190. [CrossRef] [PubMed]

30. Zhang, H.; Wu, W.; Mo, Y. Study of proton-coupled electron transfer (PCET) with four explicit diabatic states at the ab initio level. Comput. Theor. Chem. 2017, 1116, 50-58. [CrossRef]

31. Iuga, C.; Alvarez-Idaboy, J.R.; Russo, N. Antioxidant activity of trans-resveratrol toward hydroxyl and hydroperoxyl radicals: A quantum chemical and computational kinetics study. J. Org. Chem. 2012, 77, 3868-3877. [CrossRef] [PubMed]

32. Teel, A.; Watts, R.J. Degradation of carbon tetrachloride by modified Fenton's reagen. J. Hazard. Mater. 2002, 94, 179-189. [CrossRef]

33. Fang, Y.Z.; Zeng, R.L. Theory and Application of Free Radical Biology, 1st ed.; Science Press: Beijing, China, 2002; p. 17.

34. Soobrattee, M.A.; Neergheen, V.S.; Luximon-Ramma, A.; Aruoma, O.I.; Bahorun, T. Phenolics as potential antioxidant therapeutic agents: Mechanism and actions. Mutat. Res. 2005, 579, 200-213. [CrossRef] [PubMed]

35. Huang, D.; Ou, B.; Prior, R.L. The chemistry behind antioxidant capacity assays. J. Agric. Food Chem. 2005, 53, 1841-1856. [CrossRef] [PubMed]

36. Apak, R.; Özyürek, M.; Güçlü, K.; Çapanoğlu, E. Antioxidant Activity/Capacity Measurement. 1. Classification, Physicochemical Principles, Mechanisms, and Electron Transfer (ET)-Based Assays. J. Agric. Food. Chem. 2016, 64, 997-1027. [CrossRef] [PubMed]

37. Li, X.C. 2-Phenyl-4,4,5,5-tetramethylimidazoline-1-oxyl 3-Oxide (PTIO•) Radical Scavenging: A New and Simple Antioxidant Assay In Vitro. J. Agric. Food Chem. 2017, 65, 6288-6297. [CrossRef] [PubMed]

38. Goldstein, S.; Russo, A.; Samuni, A. Reactions of PTIO and carboxy-PTIO with $\bullet$ NO, $\bullet \mathrm{NO}_{2}$, and $\bullet \mathrm{O}_{2}{ }^{-}$. J. Biol. Chem. 2003, 278, 50949-50955. [CrossRef] [PubMed]

39. Lin, J.; Li, X.C.; Chen, L.; Lu, W.Z.; Chen, X.W.; Han, L.; Chen, D.F. Protective effect against hydroxyl radical-induced DNA damage and antioxidant mechanism of [6]-gingerol: A Chemical Study. B Korean Chem. Soc. 2014, 35, 1633-1638. [CrossRef]

40. Li, X.; Han, L.; Li, Y.; Zhang, J.; Chen, J.; Lu, W.; Zhao, X.; Lai, Y.; Chen, D.; Wei, G. Protective effect of Sinapine against hydroxyl radical-induced damage to mesenchymal stem cells and possible mechanisms. Chem. Pharm. Bull. (Tokyo) 2016, 64, 319-325. [CrossRef] [PubMed]

41. Li, X.C.; Gao, Y.X.; Li, F.; Liang, A.F.; Xu, Z.M.; Bai, X.Y.; Mai, W.Q.; Han, L.; Chen, D.F. Maclurin protects against hydroxyl radical-induced damages to mesenchymal stem cells: Antioxidant evaluation and mechanistic insight. Chem. Biol. Interact. 2014, 219, 221-228. [CrossRef] [PubMed]

42. Li, X.; Han, W.; Mai, W.; Wang, L. Antioxidant activity and mechanism of tetrahydroamentoflavone in vitro. Nat. Prod. Commun. 2013, 8, 787-789.

43. Chen, D.F.; Li, X.; Xu, Z.; Liu, X.; Du, S.H.; Li, H.; Zhou, J.H.; Zeng, H.P.; Hua, Z.C. Hexadecanoic acid from Buzhong Yiqi decoction induced proliferation of bone marrow mesenchymal stem cells. J. Med. Food 2010, 13, 967-970. [CrossRef] [PubMed]

44. Wang, T.T.; Zeng, G.C.; Li, X.C.; Zeng, H.P. In vitro studies on the antioxidant and protective effect of 2-substituted -8-hydroxyquinoline derivatives against $\mathrm{H}_{2} \mathrm{O}_{2}$-induced oxidative stress in bmscs. Chem. Biol. Drug Des. 2010, 75, 214-222. [CrossRef] [PubMed]

45. Wang, G.; Li, X.C.; Zeng, H.P. Synthesis, antioxidation activity of (E)-9-p-Tolyl-3-[2-(8-hydroxy-quinol2-yl)vinyl]-carbazole and (E)-9-(p-Anisyl)-3-[2-(8-hydroxy-quinol-2-yl)vinyl]-carbazole and their induction proliferation of mesenchymal stem cells. Acta Chim. Sin. 2009, 67, 974-982.

46. Benzie, I.F.F.; Strain, J.J. The ferric reducing ability of plasma (FRAP) as a measure of "antioxidant power": The FRAP analysis. Anal. Biochem. 1996, 239, 70-76. [CrossRef] [PubMed]

47. Apak, R.; Guclu, K.; Ozyurek, M.; Bektas Oglu, B.; Bener, M. Cupric ion reducing antioxidant capacity assay for food antioxidants: Vitamins, polyphenolics, and flavonoids in food extracts. Methods Mol. Biol. 2008, 477, 163-193. [PubMed]

48. Liu, J.J.; Li, X.C.; Lin, J.; Li, Y.R.; Wang, T.T.; Jiang, Q.; Chen, D.F. Sarcandra glabra (Caoshanhu) protects mesenchymal stem cells from oxidative stress: A bioevaluation and mechanistic chemistry. BMC Complement. Altern. Med. 2016, 16, 423. [CrossRef] [PubMed] 
49. Li, X.C.; Wu, X.T.; Ling, H. Correlation between antioxidant activities and phenolic contents of Radix Angelicae Sinensis (Danggui). Molecules 2009, 14, 5349-5361. [CrossRef] [PubMed]

50. Li, X.C.; Wei, G.; Wang, X.Z.; Liu, D.H.; Deng, R.D.; Li, H.; Zhou, J.H.; Li, Y.W.; Zeng, H.P.; Chen, D.F. Targeting of the Shh pathway by atractylenolides promotes chondrogenic differentiation of mesenchymal stem cells. Biol. Pharm. Bull. 2012, 35, 1328-1335. [CrossRef] [PubMed]

51. Li, X.C.; Lin, J.J.; Wang, T.T.; Huang, J.; Lin, Y.; Chen, D.F. Protective effects of dihydromyricetin against -OH-induced mesenchymal stem cells damage and mechanistic chemistry. Molecules 2016, 21, 604. [CrossRef] [PubMed]

52. Li, X.C.; Hua, Q.P.; Jiang, S.X.; Li, F.; Lin, J.; Han, L.; Hong, Y.L.; Lu, W.B.; Gao, Y.X.; Chen, D.F. Flos Chrysanthemi Indici protects against hydroxyl-induced damages to DNA and MSCs via antioxidant mechanism. J. Saudi Chem. Soc. 2015, 19, 454-460. [CrossRef]

Sample Availability: Sample of the compound E-resveratrol is available from the authors.

(C) 2018 by the authors. Licensee MDPI, Basel, Switzerland. This article is an open access article distributed under the terms and conditions of the Creative Commons Attribution (CC BY) license (http:/ / creativecommons.org/licenses/by/4.0/). 